\title{
Stability of plasmid pBR322 within Escherichia coli cells
}

\begin{abstract}
Insertion of plasmids into the bacterial cells is of great significance especially in course of the transfer of drug resistance, virulence and other traits. Retention of plasmids within the host bacteria is therefore an important factor for bacterial homeostasis. Current study inferred the pBR322 plasmid stability within the Escherichia coli competent cells. The calcium chloride heat shock method was used for the transformation purpose. The plasmid retention phenomenon was assessed through the replica plating. The results positively showed the plasmid retention within E. coli.
\end{abstract}

Keywords: pBR322, plasmid stability, Escherichia coli, replica plating
Volume 6 Issue I - 202I

\author{
Tahsin Tabassum, Tasmin Tabassum, Nafisa \\ Tabassum, Syeda Muntaka Maniha, Rashed \\ Noor
}

Department of Life Sciences (DLS), School of Environment and Life Sciences (SELS), Independent University, Bangladesh

\begin{abstract}
Correspondence: Rashed Noor, Associate Professor, Department of Life Sciences (DLS), School of Environment and Life Sciences (SELS), Independent University, Bangladesh (IUB), Plot 16, Block B, Bashundhara, Dhaka 1229, Bangladesh, Tel+880174940I45I,Email rashednoor@iub.edu.bd
\end{abstract}

Received: December II, 2020 | Published: January 27, 2021

\section{Introduction}

Plasmids, the self-replicating genetic elements, separated from the host chromosome, are widely distributed among bacteria, yeast and archea, imparting the host specific traits like adaptation to specific habitats, production of virulence factors, resistance to antibiotics, heavy metals, degradation of xenobiotics or other attributes. ${ }^{1,2}$ The general mechanisms involved in the maintenance of plasmid within the host cells have been reported as the random or active partitioning, plasmid addiction systems, horizontal gene transfer, positive selection for the plasmid encoded genes, etc. ${ }^{1,3,4}$ Plasmids like pBR322, pACYC177, pBAD24, pUC118, etc. have long been known as the common vectors (with some broad-host-range plasmid vectors with additional cloning sites i.e., the polylinker sites and the improved antibiotic-resistance genes) to genetically manipulate a range of microorganisms especially the most commonly used model bacterium Escherichia coli and some other hosts. ${ }^{5-10}$

An interesting aspect of plasmid DNA transformation into the host bacterial cell lies within the findings that the transformed plasmids can be lost during the bacterial cell growth in absence of selection pressure like the saturation of the appropriate concentration of the required antibiotics like ampicillin with the growth medium. ${ }^{11}$ In the antibiotic free medium (antibiotic representing the drug-resistance marker of the particular plasmid), the plasmid-bearing and the plasmid-free cells may differ in growth revealing a relatively slower growth rate among the transformants; i.e., the plasmid bearing cells. ${ }^{11}$ However, supplementation with low dose of the corresponding antibiotics may sustain the plasmid stability. ${ }^{11}$ Regarding the plasmid stability, several suggestive evidences include:

a. The appearance of plasmid-free cells due to the result of segregational instability of a resident plasmid;

b. The kinetics of DNA synthesis and plasmid segregation;

c. Replication and segregation of plasmid copies to daughter cells; and the

d. Dynamics of plasmid persistence in the absence of selection. ${ }^{1,12-15}$
Such segregation and selection model (SS) further suggested the inclusive study of the growth dynamics of two bacterial populations: one, consisting of plasmid containing cells and the second, consisting of plasmid-free cells, which delivered a simple system of equations whereby it was assumed that the abundance of the plasmid-free cells might increase due to the faults in the plasmid segregation machinery. ${ }^{1}$

Most recently a highly sensitive method to measure the plasmid stability in Gram-negative bacteria has been reported which is based on the counter-selection of the plasmid bearing cells using an aphparE cassette together with the kanamycin resistance marker (aph). ${ }^{16}$ Several experimental evolution studies relating to plasmid stability demonstrated the importance of selection for the plasmid presence, the compensatory evolution of the plasmid or the role of the host chromosome influencing the plasmid retention. ${ }^{17,18}$ According to these lines of experimental results, the current study was designed specifically to examine the plasmid stability in E. coli cells.

\section{Material and methods}

For the transformation of pBR322 plasmid into Escherichia coli cells, the calcium chloride heat shock method was followed. ${ }^{19}$ At first the competent cells of $E$. coli were prepared according to the standard protocol. ${ }^{20}$ Cells were washed with $0.1 \mathrm{M} \mathrm{CaCl}_{2}$ for three times in ice-cold condition. An aliquot of $1.5 \mathrm{ml}$ of competent cells was used to conduct transformation using $1 \mu \mathrm{l}$ of plasmid. The plasmid was homogeneously mixed with the competent cells and kept at $42{ }^{\circ} \mathrm{C}$ for $1 \mathrm{~min}$; and then was quickly transferred to ice $\left(0^{\circ} \mathrm{C}\right)$ and kept for 2 minutes. After such heat shock procedure, $0.5 \mathrm{ml}$ of Luria Bertani (LB) was added and kept at $37{ }^{\circ} \mathrm{C}$ water batch (with $100 \mathrm{rpm}$ ) for an hour. After this adaptation, $100 \mu \mathrm{l}$ of the culture was spread onto the LB plates containing amplicillin in $50 \mu \mathrm{g} \cdot \mathrm{mL}^{-1}$ concentration (LB ${ }^{\text {amp50 }}$, the Master Plates). Plates were incubated at $37^{\circ} \mathrm{C}$ overnight and the appearance of the transformants was observed. For replica plating of the Master Plates (M) containing the E. coli colonies retaining the pBR322 plasmids, sterile velvet cloths were used. Plates were incubated at $37^{\circ} \mathrm{C}$ for 12 hours the appearance of the transformants was observed on this Master Plate (M). Sterile velvet cloths were used to make the Replica Plate $(\mathrm{R})$ and the Control Plate $(\mathrm{C}, \mathrm{LB}$ medium without drug). 


\section{Results and discussion}

Our results showed that $E$. coli cells were transformed successfully by the plasmid pBR322; and the plasmid retention was nearly $100 \%$ as was noticed in the replica plate (Figure 1). The Master Plate was kept at $4{ }^{\circ} \mathrm{C}$ for 5 days and the replica plating was conducted in the similar way. The plasmid retention; the transformant colonies decreased by nearly $50 \%$ (results not shown). However, in such replica plating experiment, the only selection pressure was the addition of the drug ampcillin (at a concentration of $50 \mu \mathrm{g} \cdot \mathrm{mL}^{-1}$ ). Nevertheless, this data efficiently showed the plasmid retention assessment in E. coli cells. Besides, as stated above, a remarkable feature of plasmid DNA transformation into the host bacterial cell is their instability during the microbial growth in absence of the selection pressure as in the case of the current study, the drug-resistance marker, ampicillin.
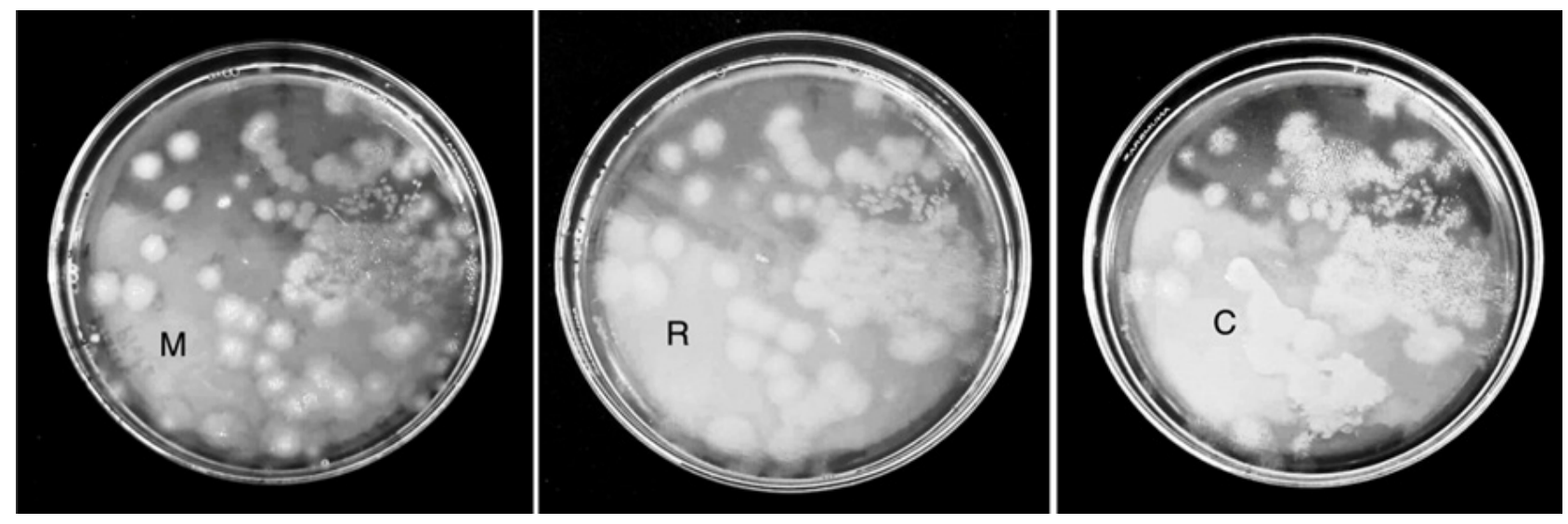

Figure I pBR322 plasmid stability within Escherichia coli cells.
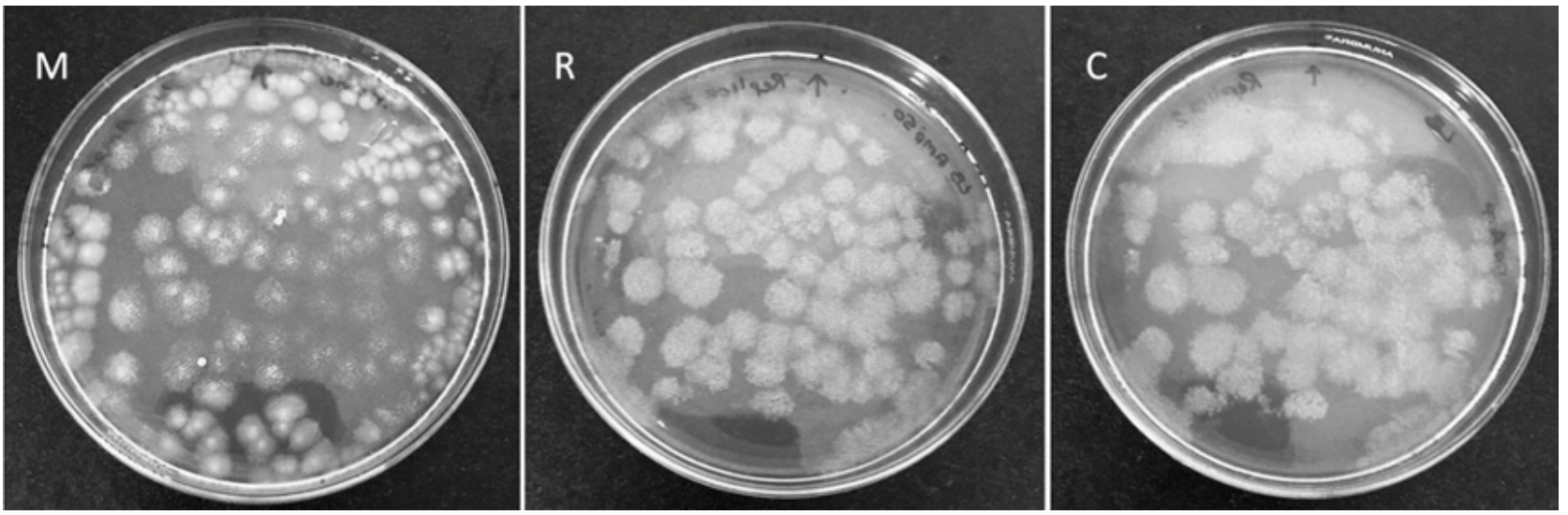

Figure 2 Estimation of pBR322 plasmid retention capacity by E. coli cells.

In the model proposed by Werbowy et al. ${ }^{1}$, it was shown that upon cell division, each daughter cell inherits a particular amount of plasmid molecules from the mother cell. At the beginning of the experiment; i.e., at the early exponential phase, all the transformants were noticed to retain the plasmids, ${ }^{1}$ which is actually not different from our observations too. In the exponential phase whereby the plasmids are expected to segregate randomly between the two daughter cells, the number of plasmid bearing cells may slightly decrease. After cell division, the inherited plasmid molecules may replicate only once per cell cycle ${ }^{1}$ which may actually lead to the loss of plasmids. One important aspect in our experiment would be pondering of the ascending concentration of the selective drug which may infer better observation of the plasmid retention capacity. Secondly, multiple hosts can be selected for the future experiments which would definitely clearly show the variations of plasmid retention capacity within different microbial species.

After transformation of pBR322 into the E. coli competent cells (as described in the Materials and Methods), the transformants were subjected to replica plating from the Master Plates (M) with the aid of sterile velvet cloths. Upon incubation for 12 hours at $37{ }^{\circ} \mathrm{C}$, the transformants were observed and enumerated on the Replica Plate (R) consisting of ampicillin antibiotc at the prescribed concentration. A Control Plate (C) was also used for the precision of the experiment.

3-ml of LB broth was inoculated with one loopful colony from the 10-days old Master Plate (as explained in Figure 1) which was kept at $6{ }^{\circ} \mathrm{C}$, and the broth culture was incubated for 4 hours till the optical density at $600 \mathrm{~nm}\left(\mathrm{OD}_{600}\right)$ reached approximately 0.6 (meaning the $\log$ phase growth). $10 \mu \mathrm{l}$ was spread onto the $\mathrm{LB}$ plates supplemented with amplicillin. Following the similar procedure as stated in Figure 1, plates were incubated at $37^{\circ} \mathrm{C}$ for 12 hours to examine the appearance of the transformants; i.e., the second Master Plate (M). Then the replica plating experiment was conducted and the retention of the transformants was noticed on Replica Plate (R). A Control Plate (denoted as C; i.e., the LB medium) was also used without the drug.

\section{Conclusion}

The study clearly showed the phenomenon of plasmid retention within the E. coli transformants. However, future experiments with the increasing concentrations of the antibiotics (serving as the drug 
resistance markers) would clarify the precise plasmid retention capacity among various natural microbial strains as well as would unravel the freuency of natural transformation of plasmids within the envirnment.

\section{Acknowledgments}

Authors are thankful to the Laboratory of Microbiology, School of Environment and Life Sciences (SELS), Independent University, Bangladesh (IUB) for the logitic supports. However, no grant was received to conduct this experiment.

\section{Conflicts of interest}

None.

\section{Funding}

None.

\section{References}

1. Werbowy O, Werbowy S, Kaczorowski T. Plasmid stability analysis based on a new theoretical model employing stochastic simulations. PLoS One. 2017;12(8):e0183512.

2. Heuer H, Smalla K. Plasmids foster diversification and adaptation of bacterial populations in soil. FEMS Microbiol Rev. 2012;36(6):10831084.

3. Harrison E, Dytham C, Hall JP, et al. Rapid compensatory evolution promotes the survival of conjugative plasmids. Mob Genet Elements. 2016;6(3):e1179074.

4. Mruk I, Kobayashi I. To be or not to be: regulation of restrictionmodification systems and other toxin-antitoxin systems. Nucleic Acids Res. 2014;42(1):70-86.

5. Murata M, Noor R, Nagamitsu $H$, et al. Novel pathway directed by $\sigma^{\mathrm{E}}$ to cause cell lysis in Escherichia coli. Genes Cells. 2012;17(3):234-247.

6. Noor R, Murata M, Nagamitsu H, et al.. Dissection of $\sigma^{\mathrm{E}}$-dependent cell lysis in Escherichia coli: roles of RpoE regulators RseA, RseB and periplasmic folding catalyst PpiD. Genes Cells. 2009a;14(7):885-99.

7. Noor R, Murata M, Yamada M. Oxidative stress as a trigger for growth phase-specific $\sigma^{\mathrm{E}}$-dependent cell lysis in Escherichia coli.J Mol Microbiol Biotechnol. 2009b;17(4):177-87.
8. Nakano Y, Yoshida Y, Yamashita Y, et al. Construction of a series of pACYC-derived plasmid vectors. Gene. 1995;162(1):157-8

9. Keen NT, Tamaki S, Kobayashi D, et al. Improved broad-host-range plasmids for DNA cloning in Gram-negative bacteria. Gene. 1988; 70(1):191-197.

10. Balbás P, Soberón X, Merino E, et al. Plasmid vector pBR322 and its special-purpose derivatives. Gene. 1986;50(1-3):3-40.

11. Sieben M, Steinhorn G, Müller C, et al. Testing plasmid stability of Escherichia coli using the Continuously Operated Shaken BIOreactor System. Biotechnol Prog. 2016;32(6):1418-1425.

12. Ponciano JM, de Gelder L, Top EM, et al. The population biology of bacterial plasmids: a hidden Markov model approach. Genetics. 2007;176(2):957-968.

13. Paulsson J, Ehrenberg M. Trade-off between segregational stability and metabolic burden: a mathematical model of plasmid ColE1 replication control. J Mol Biol. 1998;279(1):73-88.

14. Cooper NS, Brown ME, Caulcott CA. A mathematical method for analysing plasmid stability in micro-organisms. J Gen Microbiol. 1987;133(7):1871-1880.

15. Nordström K, Aagaard-Hansen H. Maintenance of bacterial plasmids: comparison of theoretical calculations and experiments with plasmid R1 in Escherichia coli. Mol Gen Genet.1984;197(1):1-7.

16. Lobato-Márquez D. Measuring Plasmid Stability in Gram-Negative Bacteria. Methods Mol Biol. 2020;2075:223-233.

17. Sota M, Yano H, Hughes JM, et al. Shifts in the host range of a promiscuous plasmid through parallel evolution of its replication initiation protein. ISME J. 2010;4(12):1568-1580.

18. Wein T, Hülter NF, Mizrahi I, et al. Emergence of plasmid stability under non-selective conditions maintains antibiotic resistance. Nat Commun. 2019;10(1):2595

19. Chang AY, Chau VWY, Landas JA, et al. Preparation of calcium competent Escherichia coli and heat-shock transformation. JEMI Methods. 2017;1:22-25.

20. Froger A, Hall JE. Transformation of plasmid DNA into E. Coli using the heat shock method. $J$ Vis Exp. 2007;6:253. 